\title{
Oral Findings in Newborn Children in and around Mangalore, Karnataka State, India
}

\author{
Dilip George Sham S. Bhat Sundeep K. Hegde \\ Department of Pedodontics and Preventive Dentistry, Yenepoya Dental College Hospital, Mangalore, Karnataka, India
}

\section{Key Words}

Epstein's pearls · Bohn's nodules · Gingival cysts of infants

\begin{abstract}
Objectives: The aims of this study were to determine the prevalence of normal findings and oral anomalies in newborn children in and around Mangalore, India, within the first week of birth. Subjects and Methods: A gloved index finger, a head torch and an extra-orally placed ruler were used to perform visual examinations in 1,038 newborn babies, who were selected by convenience sampling. The babies were examined by one of the investigators (D.G.). Normal findings like the location of upper labial midline frenum, symmetry of alveolar ridges, anteroposterior/buccolingual and vertical relationship of the alveolar ridges, and oral anomalies like white inclusion cysts that are gingival cyst of infants, Epstein's pearls and Bohn's nodules were recorded in a standard format. The findings were statistically analysed. Results: Open bite was present in 102 (9.8\%) children. In the anteroposterior relationship, 1,035 (99.7\%) had the mandible distal to maxilla. In the buccolingual relationship, the mandible was lingual to the maxilla in 1,035 neonates (99.7\%). Gingival cyst of infants was present in 143 (13.8\%) of the neonates, Epstein's pearls in 365 (35.2\%) and Bohn's nodules in 492 (47.4\%). Conclusion: The present study exhibits the prevalence of normal findings and anomalies in the neonates. Longitudinal studies are required to assess any significance of the anteroposterior, buccolingual and vertical relationships of the gum pads in the neonates to the future development of occlusion.
\end{abstract}

Copyright $\odot 2008$ S. Karger AG, Basel

\section{Introduction}

Many features of the infant mouth are unique and peculiar to this period of development. The frequency of inclusion cysts is high in newborns, but they are rarely seen after 3 months of age [1]. However, studies have not been done to assess the prevalence and significance of these abnormalities, especially in the Indian population. Hence, the objectives of this study were to record the normal findings and oral anomalies in newborns in and around Mangalore within the first week of birth, and to determine the prevalence of these findings.

\section{Materials and Methods}

The investigation was planned as a population-based study. It aimed to include all children born in and around Mangalore city. Prior to the commencement of the study, ethical clearance was obtained from the Ethics Committee in our institution. The study was conducted in the following institutions in the postnatal ward: Yenepoya Medical College Hospital, Deralakatte; Father Muller Medical College Hospital, Kankanady; AJ Institute of Medical Sciences, Kuntikana, Mangalore.

All babies were examined within 1 week of birth with the parents' oral consent. Convenience sampling was used in each hospital. The intra-oral findings in the neonate were observed by visual examination, which was performed using a gloved index finger, head torch and an extra-orally placed ruler. A standard format for the data was prepared to record the necessary details required for the survey. To standardize the diagnostic criteria, preliminary examinations were performed on 30 newborns who were not included in the analysis. The demographic details of the mother, i.e. name, age, address, telephone number, hospital inpatient number and hospital name, were obtained from the records. Date of birth,

\section{KARGER}

Fax +41613061234 E-Mail karger@karger.ch www.karger.com
Dr. Sham S. Bhat

Department of Pedodontics and Preventive Dentistry

Yenepoya Dental College Hospital, Nithyananda Nagar PO, Deralakatte

Mangalore 575 018, Karnataka (India)

Tel. +91 824220 4668, ext. 227, Fax +91 824220 4663, E-Mail drdilpu@gmail.com 
gender of the newborn, gestational age, mode of birth, length, weight, Apgar scores at 1 and $5 \mathrm{~min}$, birth complications, medical complications of the mother during pregnancy and medical diagnosis of the newborn at birth, if any, were obtained from the neonatal birth record. The oral mucosa was systematically examined for the following: location of the maxillary labial midline frenum, symmetry of the alveolar ridges and developmental white inclusion cysts (including gingival cysts of newborn, Epstein's pearls and Bohn's nodules). Also, the presence of Fordyce's spots/granules, ankyloglossia and natal teeth were noted. All of the above were seen by softly opening the jaws of the neonate and close observation with the help of light from a head torch. The anteroposterior, buccolingual and vertical relationships (open bite) of the alveolar ridges were assessed by carefully bringing the jaws together, as previously described by Flinck et al. [2]. Any other relevant extra-oral and intra-oral findings, like retrognathia and candidiasis of the tongue, were also recorded.

A total of 1,038 neonates were examined, of whom 555 were males and 483 females. Of the 1,038 neonates examined, 147 (14.2\%) were born prematurely, 79 (7.6\%) were preterm babies with a low birth weight and $14(1.3 \%)$ were twins. The statistical analyses used in the study were the arithmetic means, standard deviations and $\chi^{2}$ tests, which were performed using SPSS software version 11.5.

\section{Results}

The mean gestational age and body weight were 38 weeks and $2.86 \mathrm{~kg}$, respectively. The mean length and head circumference of the neonates were 48.5 and 33.7 $\mathrm{cm}$, respectively. Apgar scores at 1 and at $5 \mathrm{~min}$ showed means of 7 and 9, respectively. Regarding medical complications, 11 mothers had oligohydramnios, 20 pregnancy-induced hypertension, 8 placenta previa, 4 congenital heart disease and 3 gestational diabetes. One mother was HIV positive and 2 mothers infected with hepatitis B. The medical diagnoses of the neonates at birth revealed 2 children with Pierre Robinson syndrome, 1 with DandyWalker syndrome, and 3 with cleft lip and palate.

\section{Normal Findings}

Regarding the location of the maxillary labial midline frenum, it was buccal of the alveolar ridge in 713 newborns $(68.7 \%)$ and on the crest of the alveolar ridge in 325 newborns (31.3\%). There were no cases where the frenum was located palatal of the alveolar ridge. One neonate had a hypertrophied labial frenum. Symmetrical alveolar ridges were noted in 1,015 of the newborns (97.8\%) and 23 (2.2\%) showed asymmetry. Regarding the anteroposterior relationships of the alveolar ridges, 1,036 (99.8\%) had the mandible distal to maxilla and $2(0.2 \%)$ had them edge to edge. There was no case where the mandible was mesial to maxilla. With regards to the buccolingual rela-

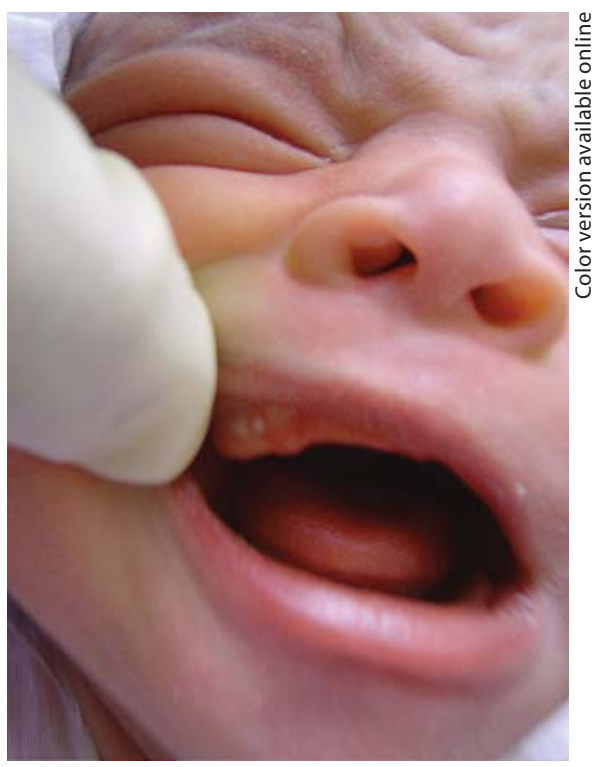

Fig. 1. Gingival cyst of infants.

tionship of the alveolar ridges, in 1,035 newborns (99.7\%) the mandible was lingual to the maxilla and in $3(0.3 \%)$ they were edge to edge. No case was recorded where the mandible was buccal to the maxilla.

\section{Oral Anomalies}

The gingival cyst of infants (fig. 1) was present in 143 neonates (13.8\%): 112 (10.8\%) on the alveolar region, 19 (1.8\%) palatally and $12(1.2 \%)$ on both regions, and in 5 cases gingival cyst of infants was present also on the alveolar ridge. The diameter of the cysts varied from 0.1 to $2.0 \mathrm{~mm}$. The cysts were pearl white in colour in all the cases. Epstein's pearls (fig. 2) were present in 365 newborn (35.2\%), and were located in the midline within the median raphae of the hard palate in the maxilla. Bohn's nodules (fig. 3) were present in 492 newborn (47.4\%), which were located at the junction of the hard and soft palate, adjacent to the midpalatal raphae. Fordyce's spots were present in 8 neonates $(0.8 \%)$ on the buccal mucosa. Ankyloglossia was present in only 1 newborn. Natal teeth were recorded in 3 newborn in the mandibular midline region, while 1 newborn presented with 2 natal teeth.

\section{Discussion}

\section{Normal Findings}

A study conducted by Flinck et al. [2] showed the maxillary labial midline frenum to be located buccal to the 


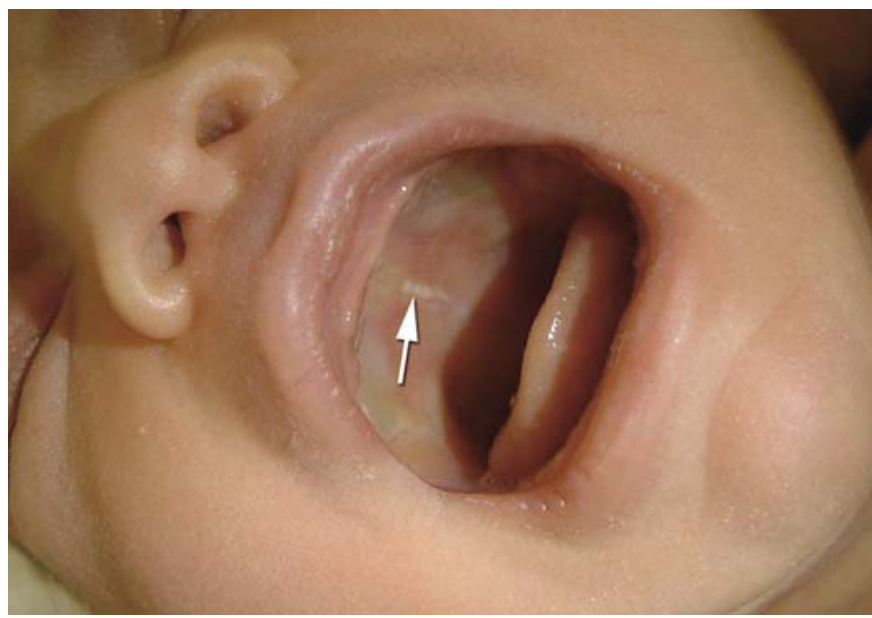

Fig. 2. Epstein's pearls.

alveolar ridge in $2.5 \%$ of the cases, at the crest of the alveolar ridge in $76.7 \%$ and palatal to the alveolar ridge in $16.7 \%$. In the present study, $68.7 \%$ of the cases demonstrated frenum location buccal to the alveolar ridge and $31.3 \%$ at the crest of the alveolar ridge, while no cases had the frenum located palatal to the alveolar ridge. The probable reasons for the different findings are effects of racial differences and sample variations. The labial frenum is a band of elastic tissue that originates in the lip and inserts in the attached gingiva at the midline of the maxilla [3]. However, a more prominent maxillary labial frenum inserted on the crest of the alveolar ridge and incisive papilla may be a normal finding in infants. The attachment will relocate apically with vertical growth of the alveolus [4]. Ranly [5] has also stated that the labial frenum may be continuous with the incisive papilla in $25 \%$ of newborns.

The maxillary and mandibular gum pads have frequently been illustrated by describing a vertical opening in the anterior area, with only the posterior segments touching. More often, the maxillary gum demonstrates a slight overlap relative to the mandibular gum pad, both horizontally and vertically. Thereby, the opposing surfaces of the pads provide a more efficient way of squeezing milk during breastfeeding [6]. Some maintain that an anterior open bite is normal, and maybe even a prerequisite for a subsequent normal incisor relationship [7]. This study recorded an open bite in $98.8 \%$ of the cases, defined as a vertical space between the anterior segments of the mandibular and maxillary ridges at time of posterior contact. Studies done by Clinch [8] have shown an open bite prevalence of $39.8 \%$ in newborns. A study by Simpson and Cheung [9] has shown a prevalence as low as $1.33 \%$.

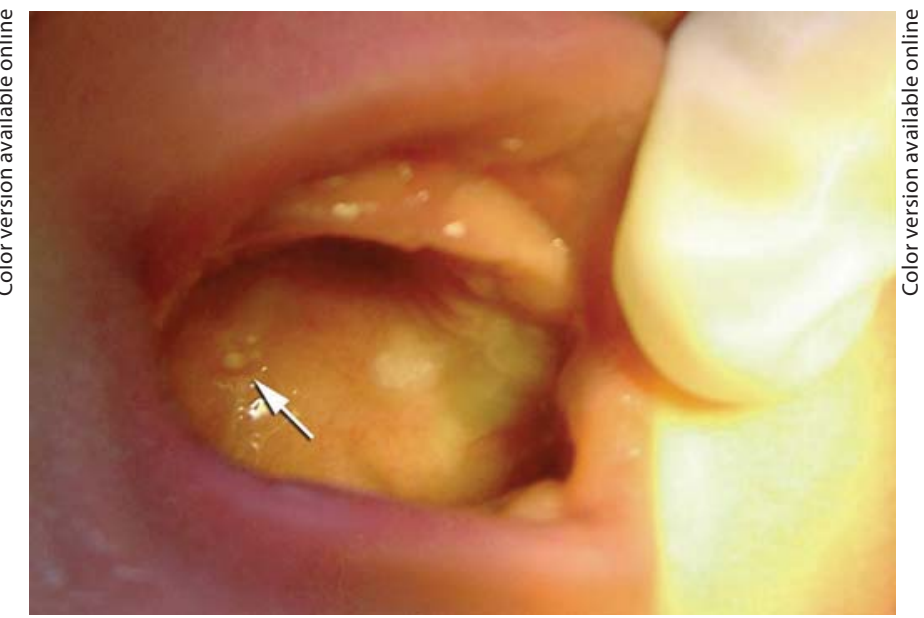

Fig. 3. Bohn's nodules.

Clinch [8] has stated that an anterior open bite may be favourable for later development of normal occlusion, while Simpson and Cheung [9] maintain that the type of anterior relationship between the alveolar ridges at birth is irrelevant for the development of normal occlusion.

Flinck et al. [2] reported that $99 \%$ of the cases had the mandible located distal to maxilla, while $1 \%$ had them edge to edge. Similarly to this study, they found no cases with the mandibular ridge located mesial to the maxillary ridge. The most prevalent relationship in this survey was a lingual position of the mandible relative to maxilla in $99.7 \%$ of the cases, with only 3 cases with an edge-toedge relationship. No cases had the mandibular ridge anterior to the maxillary. Flinck et al. [2] reported that $97.6 \%$ of the cases had the mandible lingual to the maxilla and in $2.2 \%$ they were edge to edge.

Simpson and Cheung [9] assessed the relationship of the gum pads using casts and photographs, while the assessments in the present study were based on clinical examinations.

Clinch [8] classified the relationship of the gum pads in 3 categories: (1) the mandibular arch positioned slightly lingual to the maxillary arch in both the incisor and the molar region (70\%); (2) the mandibular arch positioned slightly lingual and distal to the maxillary arch in the molar region, but definitely distal in the incisor region (27\%); (3) the mandibular arch positioned definitely distal in both the molar and the incisor regions (3\%).

Oral Anomalies

Fromm [10] classified conditions affecting newborns as Epstein's pearls, Bohn's nodules and dental lamina 
cysts. Palatally located cysts in newborns were first described by Alois Epstein, and are often referred to as Epstein's pearls. Cysts located on the alveolar ridges are named Bohn's nodules, after his description in 1866. In 1880, Epstein classified all palatal cysts as inclusion cysts; while Bohn classified cysts in the alveolar ridges as mucous gland cysts [2]. Later studies have shown cysts are microkeratocysts. Moreillon and Schroeder [11] studied material from fetuses between 8 and 22 weeks of age and detected microkeratocysts in the alveolar ridges as early as $9-10$ weeks. They also found and as many as $110-120$ such cysts in fetuses of about 17-18 weeks of age. The authors assumed that these cysts might increase in number after week 22. The mechanisms behind the disappearance of the cysts in postnatal life have been attributed to a discharge of cystic keratin at the time of fusion of the cyst walls with the oral epithelium. However, it has been suggested that part of the cystic epithelium may remain inactive in the midpalatal region of the adult gingiva. The appearance of palatal cysts seems to be limited to the fetal period, whereas alveolar cysts derived from the dental lamina may appear also during postnatal life. Palatal cysts in the newborn were described as small superficial microcysts of the midpalatal raphae arising from the epithelial inclusions along the fusion of the palatal folds; thus, including both Epstein's pearls and Bohn's nodules. Gingival cysts in newborns are located on the alveolar ridge area and arise from remnants of the degenerating dental lamina [12]. Presently, they are described as Epstein's pearls, which occur along the median palatal raphae and arise from the epithelium entrapped along the line of fusion. Bohn's nodules are scattered over the junction of the hard and soft palate, and are derived from minor salivary glands. However, these 2 terms have been used almost interchangeably in the literature. They have also been used to describe gingival cysts in newborns of similar appearance to lesions of dental lamina origin [13].

In this study, we observed gingival cysts of infants (alveolar cysts) in 143 of the newborns (13.8\%). Among 122 of the newborns (10.8\%), the cysts were located only on the alveolar ridge, among 19 newborns $(1.8 \%)$ only on the palate, and in $12(1.2 \%)$ the cysts were located on the alveolar ridge as well as the palate. Only 5 cases demonstrated cysts on the mandibular ridge. Jorgenson et al. [14] found alveolar cysts in $53.5 \%$ of white children in the USA. Friend et al. [15] recorded alveolar cysts in $25 \%$ of children from Tennessee, USA. Cataldo and Berkman [16] reported a $36.5 \%$ prevalence of cysts on the maxillary alveolar ridge. Liu and Huang [12] reported cysts in 79\% of Taiwanese newborns. In this survey, Epstein's pearls were found in $35.2 \%$ and Bohn's nodules in $47.4 \%$ of the newborn. Considering both types of subgroups of palatal cysts, our study recorded the prevalence of palatal cysts to be $55 \%$. Jorgenson et al. [14] recorded a prevalence of 72.9\%; Friend et al. [15], 58.2\%; Liu and Huang [12], 86\%; Cataldo and Berkman [16], 65\%. The present study also demonstrated that palatal cysts are more prevalent than alveolar cysts in newborns, in keeping with findings from earlier studies. Friend et al. [15] also concluded that palatal cysts were 2.5 times more likely to occur in white than black newborns. The same was noted for alveolar cysts. The samples in this study were only Indians of Asian origin, precluding detection of any racial predilections.

The terms natal and neonatal teeth refer only to the time of eruption without any reference to the origin of the tooth germ. The crowns of natal and neonatal teeth are either well formed or discolored with an irregular surface. They are mostly mobile, due to either short or missing roots. The surrounding gingival tissues are typically normal. The vast majority (80\%) are primary teeth, and the remainder are permanent supernumerary teeth. The majority $(80-90 \%)$ are found in the mandibular incisor region. The exception is cleft lip and palate cases, which tend to show natal and neonatal teeth in the cleft area. Some report that natal and neonatal teeth are associated with developmental anomalies and syndromes [12]. Kates et al. [17] reported a prevalence of 1/1,397 (0.07\%); King and Lee [18], 1/1,324 (0.07\%); Friend et al [15], 1/500 (0.7\%); Bjuggren [19], 1/1,524; Liu et al. [12], 1/140 (0.9\%). This study recorded a prevalence of $3 / 1,038(0.3 \%)$ for the presence of natal teeth.

\section{Acknowledgements}

The authors wish to thank the management and the staff of the Department of Obstetrics and Gynecology, Pediatrics and Neonatal Intensive Care Unit of Yenepoya Medical College Hospital; Father Muller Medical College Hospital; AJ Institute of Medical Sciences; and also all the little ones and their parents who cooperated towards the successful completion of the study.

References

George/Bhat/Hegde
1 Donley CL, Nelson LP: Comparison of palatal and alveolar cysts of the newborn in premature and full-term infants. Pediatr Dent 2000;22:321-324.

-2 Flinck A, Paludan A, Matsson L, Holm AK, Axelsson I: Oral findings in a group of newborn Swedish children. Int J Pediatr Dent 1994;4:67-73. 
3 Behrman RE, Kliegman RM, Jenson HB: Nelson Textbook of Pediatrics, ed 17. New Delhi, Elsevier, 2004, p 234.

4 Edwards JG: The diastema, the frenum, the frenectomy: a clinical study. Am J Orthod 1977;71:489-508.

5 Ranly DM: Early orofacial development. Clin Pediatr Dent 1998;22:267-275.

6 Bishara SE: Textbook of Orthodontics (Indian reprint). New Delhi, Elsevier, 2004, p 54.

7 Moyers RE: Handbook of Orthodontics, ed 4. Chicago, Yearbook Medical Publishers, 1988, p 105

8 Clinch L: Variations in the degree of overbite between birth and three years. Dent Rec (London) 1938;58:585-597.
Simpson WJ, Cheung DK: Gum pad relationships of infants at birth. J Can Dent Assoc (Tor) 1973;39:182-188.

10 Fromm A: Epstein's pearls, Bohn's nodules and inclusion-cysts of the oral cavity. J Dent Child 1967;34:275-287.

1 Moreillon MC, Schroeder HE: Numerical frequency of epithelial abnormalities, particularly microkeratocysts, in the developing human oral mucosa. Oral Surg Oral Med Oral Pathol 1982;53:44-55.

12 Liu MH, Huang WH: Oral abnormalities in Taiwanese newborns. J Dent Child (Chic) 2004;71:118-120.

13 Neville BW, Damm DD, Allen CM, Bouquot JE: Oral and Maxillofacial Pathology, ed 2. New Dehli, Elsevier, 2004, p 25.

14 Jorgenson RJ, Sharpio SD, Salinas CF, Levin LS: Intraoral findings and anomalies in neonates. Pediatrics 1982;69:577-582.
5 Friend GW, Harris EF, Mincer $\mathrm{HH}$, Fong TL, Carruth KR: Oral anomalies in the neonate, by race and gender, in an urban setting. Pediatr Dent 1990;12:157-161.

16 Cataldo E, Berkman MD: Cysts of the oral mucosa in newborns. Am J Dis Child 1968; 116:44-48.

17 Kates GA, Needleman HL, Holmes LB: Natal and neonatal teeth: a clinical study. J Am Dent Assoc 1984;109:441-443.

$>18$ King NM, Lee AM: Prematurely erupted teeth in newborn infants. J Pediatr 1989;114: 807-809.

19 Bjuggren G: Premature eruption in the primary dentition: a clinical and radiological study. Sven Tandlak Tidskr 1973;66:343355 . 